\title{
A Case Study of Formal Translation of Tang Poetry
}

\author{
Tingshu $\mathrm{Hu}$ \\ Faculty of Foreign Languages, Huaiyin Institute of Technology, Huai'an, China
}

\begin{abstract}
The beauty of Tang poetry is expressed in the combination of content and form. If the form is not well reproduced in the process of translation, the integrity of Tang poetry would be impaired to a great extent. By looking at different translations of Tang poetry, it is found that formal reproduction happens where there already exist the similar poetic forms in the target language; such forms as line length, poetic type, rhyme, rhythm and parallelism are full-reproducible; such form as tonal pattern is semi-reproducible; and some forms, such as pun, intertextuality and palindrome, are irreproducible because they are peculiar to Tang poetry and cannot exist outside language due to the differences of two languages.
\end{abstract}

Index Terms - empirical research, formal translation, Tang poetry

\section{INTRODUCTION}

This paper addresses formal translation of Tang poetry (Lü shi and Jue ju), with an intention to reveal what forms of Tang poetry can and/or cannot be reproduced in the target language. In attempting to understand the formal properties of Tang poetry, it is important to define the form of Tang poetry. Generally speaking, the form of Tang poetry refers to its peculiar metrical arrangements and inherent elements which distinguish Tang poetry from other literary genres, including tonal pattern, rhyme, rhythm, line length, poetic type, and some other forms, such as parallelism, pun, intertextuality and palindrome, which can be roughly classified into two forms: musical form (tonal pattern, rhyme and rhythm) and visual form (line length, poetic type, parallelism, intertextuality and palindrome).

Zhu Guangqian (2008) holds that the form of poetry should be considered as the soul of poetry. Among all the information carried by poetry, the sense or content is merely a kind of low-level information, whereas the style or form, such as sound, rhyme and rhythm, is a kind of high-level information. In translating poetry, if a translator only reproduces the low-level information, what is translated is not poetry but prose. Only when the high-level information is reproduced, can the translated poem be a poem (Yang Zijian \& Liu Xueyun, 2003).

The beauty of Tang poetry is expressed in the combination of content and form. If the form is not well reproduced in the target text, the beauty of the original would be impaired to a great extent. Hence, it is significant to see how the translators have dealt with the forms of Tang poetry in their translations.

\section{OVERVIEW OF THE RESEARCH}

Academically, the intent of this paper is to support efforts to increase an understanding of the formal properties of Tang poetry and how to reproduce its forms in the target language. However, thus far little of research has been conducted on what forms can and/or cannot be reproduced in the target language and how to reproduce the forms of Tang poetry in the translation process.

According to the existing research on translation of Tang poetry on CNKI by June, 2013, the debates on formal translation are mainly centered on literal translation or liberal translation, translatability or untranslatability, content or form, and faithfulness or beauty, etc. For example, some scholars opt to sacrifice form for spirit (e.g. Liu Yingkai, 1989); some prefer to sacrifice content for form (e.g. Jiang Feng, 1995); some try to seek for a compromise between form and spirit (e.g. Gao Yukun, 1994); some tend to alter the source text form to cater to the target audience (e.g. Zhang Zhizhong, 2007). Some postgraduate students have also studied formal translation of Tang poetry in their theses. However, they merely lay stress on its necessity and importance without further exploration into formal translation itself (Li Hongqi, 2009; Xu Xiufeng, 2006; Guo Ying, 2006; Wu Dilong, 2010).

Besides, some translators or scholars in China study Tang poetry translation and propose important theories or methods based on their own translation practice, which are greatly influential in studying poetic translation. For example, Xu Yuanzhong (1984) puts forward his famous "three beauties" theory (beauty in sense, in sound and in form). $\mathrm{Wu}$ Juntao (1991) holds that a translator should find the substitute in the target language. For instance, a five-charactered line can be translated into an English poetic line of five, six or seven feet. The tonal pattern of Chinese characters can be substituted with iambic, trochaic, anapest and dactylic feet. Zhu Guangqian (2008) argues that 顿 ("caesura") in Chinese is equal to foot in English, and caesura can be substituted with foot in the process of translation. Liu Zhongde (1991) maintains that it is better to translate metrical poetry in the form of metrical poetry if the meter of the source text is preserved and the sense is not lost. 
In the existing research on translation of Tang poetry, attention is more paid to translation of poetic content, image, feeling, spirit and sense than to formal translation. This paper is an attempt on its formal translation.

\section{CASe Studies}

In order to explore what forms can and/or cannot be reproduced in the target language, formal translation of Tang poetry is respectively examined from tonal pattern, line length, poetic type, rhyme, rhythm, parallelism, pun, intertextuality and palindrome.

\section{A. Tonal Pattern}

Chinese characters are characterized by the level tone and the oblique tone, whereas English words are characterized by the stressed syllable and the unstressed syllable. In English poetry, the basic metrical patterns are: iamb, trochee, anapest, dactyl, spondee and pyrrhic.

Theoretically, a level tone and an oblique tone can be substituted by iamb; an oblique tone and a level tone by trochee; two level tones and an oblique tone by anapest; an oblique tone and two level tones by dactyl. In fact, it is difficult to achieve these substitutions fully in the process of translation, but the translator can use some flexible methods to reproduce the original effect of tonal pattern in the target language. For example,

ST: 独坐敬亭山（李白）

$$
\begin{aligned}
& \text { 众鸟高飞尽, 孤云独去闲。 } \\
& ++--+--++- \\
& \text { 相看两不庈, 只有敬亨山。 } \\
& --+++\quad+++--
\end{aligned}
$$

Notes: "—" stands for a level tone or an unstressed syllable and "+" for an oblique tone or an stressed syllable; ST stands for the source text and TT stands for the target text (same as below).

TT 1: Alone on the Ching-ting Hills (Trans. Cai Tinggan)

The birds have flown away on pinions high,

A cloud in heedless mood goes floating by.

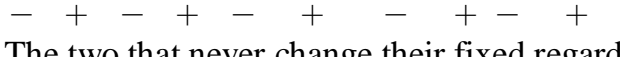

The two that never change their fixed regard,

Are ye, fair Ching-ting Hills, and I, your bard.

$-+-+-+-+-+$

TT 2: Sitting Alone Facing Peak Jingting (Trans. Xu Yuanzhong)

All birds have flown away, so high,

$-+-+-+-+$

A lonely cloud drifts on, so free.

$-+-+-+-+$

We are not tired, the Peak and I,

$-+-+-+-+$

Nor I of him, nor he of me.

$-+-+-+-+$

The tonal pattern of the source text conforms to the metrical pattern of Tang poetry strictly and reveals its musical beauty. The two translations read natural, the tonal patterns of which also reveal their musical beauty. However, the tonal patterns of Chinese and English are two parallels that do not intersect owing to the peculiarities of the two languages and it is difficult to transplant the metrical pattern of Tang poetry into English poetry completely. TT 1 adopts an iambic pentameter and TT 2 adopts an iambic tetrameter. Both of them employ an iamb (unstressed and stressed) to reproduce the tonal pattern (level and oblique) of the source text. That is to say, the two renditions achieve the original effect of tonal pattern to a certain extent, which shows the tonal pattern of Tang poetry is semi-reproducible.

\section{B. Line Length}

In Tang poetry, each poetic line consists of five characters or seven characters. Each Chinese character is characterized by monosyllable whereas each English word can bear more than one syllable. Hence, in translating Tang poetry, one Chinese character cannot match one English word. However, one character can roughly match one foot or two English syllables.

Generally speaking, the basic types of English foot include monometer, diameter, trimeter, tetrameter, pentameter, hexameter, heptameter and octameter. In the process of translation, five-charactered lines can be translated into pentameter lines, and seven-charactered lines can be translated into heptameter lines. Thus, the line length of Tang poetry and English poetry is more or less regulated and the formal beauty of Tang poetry can be reproduced in the target text to a great extent. For example, 
ST: 登鹳雀楼（王之涣）

白日依山尽，黄河入海流。

欲穷千里目, 更上一层楼。

TT: An Ascent to Stork Hall (Trans. Xu Zhongjie)

The setting sun behind the mountains glows,

The muddy Yellow River seawards flow.

If more distant views are what you desire,

You simply clime up a storey higher.

Each line of the source text contains five characters. Xu Zhongjie translates it in an iambic pentameter, i.e. five feet (ten syllables) per line, to match five characters of each line in the source text. To a great extent, Xu reproduces the line length of the original and retains the regular beauty in his rendition.

ST: 闺怨 (王昌龄)

闺中少妇不知愁，春日凝妆上翠楼。

忽见陌头杨柳色, 悔叫夫婿受封侯。

TT: At the Wars (Trans. H. A. Giles)

See the young wife whose bosom ne'er has ached with cruel pain!

In gay array she mounts the tower when spring comes around again.

Sudden she sees the willow trees their newest green put on,

And sighs for her husband far away in search of glory gone.

Giles takes advantage of English run-on line to translate each line of the source text into two lines. However, he does not use punctuation marks at the end of the odd lines and the first letter of each even line is not capitalized. His purpose of doing so is to try to preserve the line length of the source text and make the translation effect as a four-line poem because the source text is a four-line poem. Theoretically, Giles' translation is not an ottava rima because the line length of the ottava rima generally adopts an iambic pentameter, whereas the odd lines of Giles' rendition contain four feet and the even lines contain three feet.

It would seem to follow that Giles adopts an iambic heptameter, i.e. seven feet per line, to accord with seven characters of the source text. Obviously, Giles is greatly influenced by Tang poetry in the process of translation, but he is not bold enough to translate it in the form of four lines. That is to say, it is possible to translate the source text in the form of four lines with the line length of seven feet using the end-stopped line instead of the run-on line.

\section{Poetic Type}

Tang poetry (Jue ju and Lü shi) mainly consists of four lines or eight lines. However, the poetic type of English poetry is more complicated than that of Tang poetry. The poetic types of English poetry mainly include couplet, tercet, quatrain, quintet, rhyme royal, ottava rima, Spenserian stanza and sonnet.

In translating Tang poetry into English, the poetic types of quatrain and ottava rima can be adopted because the styles of quatrain and Jue ju have a lot in common, and it is true of ottava rima and Lü shi. A quatrain refers to a four-line poem or stanza with the rhyme schemes: $\mathrm{ABAB}$ or $\mathrm{AABB}$ or ABBA or AAAA; an ottava rima refers to a stanza consisting of eight lines of iambic pentameter with the rhyme of ABAB ABCC. For example,

ST: 静夜思（李白）

床前明月光, 疑是地上霜。

举头望明月，低头思故乡。

TT: A Tranquil Night (Trans. Xu Yuanzhong)

Before my bed I see a silver light,

I think the ground is covered with hoar frost.

Raising my head, I find the full moon bright,

And bowing down, in thoughts of home I'm lost.

The source text is a Jue $j u$, consisting of four lines. In the translation, the translator renders this poem in the form of quatrain in order to reproduce the poetic type of the source text. In other words, the line division of the rendition is similar to that of the source text and the poetic type of the original is well preserved in the target text.

ST: 登金陵风凰台（李白）

凤凰台上凤凰游，凤去台空江自流。

吴宫花草埋幽径，晋代衣冠成古丘。

三山半落青天外, 二水中分白路洲。

总为浮云能蔽日, 长安不见使人愁。

TT: On Phoenix Terrace at Jinling (Trans. Xu Yuanzhong)

On phoenix Terrace once phoenixes came to sing;

The birds are gone but still roll on the river's waves.

The ruined palace's buried 'neath the weeds in spring;

The ancient sages in caps and gowns all lie in graves. 
The three-peak'd mountain is half lost in azure sky;

The two-fork'd stream by Egret Isle is kept apart.

As floating clouds can vail the bright sun from the eye;

Imperial Court, now out of sight, saddens my heart.

The source text is a Lü shi, consisting of eight lines. Xu Yuanzhong renders it into an English metrical poem. Xu adopts the pattern of eight lines in his translation in order to preserve the poetic type of the source text. In this way, the original poetic type is greatly reproduced in the target text.

The above two examples are about the translation of poetic type. In a word, the poetic type of Tang poetry can be fully transplanted into English owing to many similarities shared by English quatrain and $J u e ~ j u$, as well as ottava rima and $L \ddot{u}$ shi.

\section{Rhyme}

The rhyme scheme refers to any fixed pattern of rhymes characterizing a whole poem or its stanzas. The rhyme scheme of English poetry is closely connected with the poetic type. In other words, the choice of rhyme scheme is greatly determined by the poetic type. Each poetic type has its own conventional rhyme schemes. Although the poetic types of English poetry (quatrain and ottava rima) and Tang poetry ( $J u e$ ju and Lü shi) have much in common, the rhyme schemes of them are different. Generally speaking, the basic rhyme scheme of $J u e j u$ includes AABA or ABCB, and $L \ddot{i}$ shi includes AABACADA or ABCBDBEB, while the rhyme scheme of quatrain is $\mathrm{ABAB}$, or AABB, or ABBA, or AAAA, etc., and ottava rima is ABABABCC. For example,

ST: 春怨 (金昌绪)

打起黄莺儿, A 莫教枝上啼。B

啼时惊妾梦, $\mathrm{C}$ 不得到辽西。 $\mathrm{B}$

TT 1: A Lover's Dream (Trans. W. Fletcher)

$\mathrm{Oh}$, drive the golden orioles A

From off our garden tree! B

Their warbling broke the dream wherein $\mathrm{C}$

My lover smiled to me. B

TT 2: A Complaint in Spring (Trans. Xu Yuanzhong)

Drive orioles off the tree, A

For their songs awake me. A

From dreaming of my dear, B

Far off on the frontier. B

TT 3: Spring Lament (Trans. Zhang Tingchen \& B. Wilson)

Shoo that oriole away!

Don't let him sing!

If from these dreams I wake A

I'll never reach Liaoning.

Notes: Liaoning - Far northern border outpost where the speaker's husband has been sent to fight.

The source text is a Jue $j u$ with the rhyme scheme of ABCB. In TT 1, the translator adopts the rhyme scheme of $\mathrm{ABCB}$, which is the same as the source text. This rendition was highly praised by Lü Shuxiang, and he said, "The original is rimed, and so is the translation, e.g. tree and me. The English translation of the poem has a rhythm pattern in the form of weak and strong stresses corresponding to that of the Chinese original in the form of level and oblique tones." (Liu Zhongde, 1991, p. 110)

In TT 2, Xu Yuanzhong employs the rhyme scheme of AABB, which is one of the rhyme schemes of English quatrain. In TT 3, Zhang Tingchen and B. Wilson use the rhyme scheme of ABAB, which is also one of the rhyme schemes of English quatrain. The rhyme scheme of the original is full-reproducible in TT 1, but lost in both TT 2 and TT 3 .

The following is the translation of Lü shi.

ST: 春夜喜雨 (杜甫)

好雨知时节, $\mathrm{A}$ 当春乃发生。B
随风潜入夜, $\mathrm{C}$ 润物细无声。B
野径云俱黑, $\mathrm{D}$ 江船火独明。B
晓看红湿处, $\mathrm{E}$ 花重锦官城。B

TT: Glad at Raining in a Spring Night (Trans. Sun Dayu)

Gracious raining knoweth its timely season;

Down it cometh promptly during springtide.

Following breezes it slinketh by at nightfall,

B

Things to soothe, minutely, mutely to bide.

C

Topping with paths, clouds amass the loom black, D

Lights on a river barque alone do shine bright. B

Look ye by dawn wherever red and moistened: E 
Flowers blow the Brocade-robed Officials' Town with delight. B

The source text is written by $\mathrm{Du} \mathrm{Fu}$, each line of which paints a picture of "spring," "night" and "rain" to depict the poet's joy. The rhyme scheme of the original is ABCBDBEB, with the even lines rhyming BBBB. The rhyme scheme of the translation is also ABCBDBEB, which is identical with that of the source text.

The above two examples show that rhyme is shared by both Tang poetry and English poetry and it can be fully transplanted into the target language.

\section{E. Rhythm}

As for English poetry, the rhythm pattern is mostly often established by a fairly regular number of syllables with a relatively fixed sequence of stressed and unstressed syllables. The basic unit of Tang poetry is a caesura, and English poetry is a foot. It is possible to make the number of feet equal to that of caesuras. When Tang poetry is translated into English, a caesura can be substituted by a foot. For example,

ST: 静夜思 (李白)

床前/明月/光, 疑是/地上/霜。

举头/望/明月，低头/思/故乡。

TT: Still Night Thoughts (Trans. Zhao Zhentao)

Moonlight /before /my bed,

Could it /be frost /instead?

Head up, /I watch /the moon;

Head down, /I think /of home.

Generally speaking, each line of a five-charactered Tang poem contains three caesuras with the rhythm pattern of $2 / 2 / 1$ or $2 / 1 / 2$. Zhao Zhentao adopts a tetrameter (i.e. three feet per line) to translate the source text because each line of the source text contains three caesuras. The number of rhythms per line of the target text is identical with that of the source text. The rhythm of the source text is fully reproduced in the target language.

$\mathrm{ST}$ : 金缕衣（无名氏）

劝君/莫惜/金缕/衣, 劝君/惜取/少年/时。

花开/堪折/直/须折, 莫待/无花/空/折枝。

TT: The Golden Dress (Trans. Xu Yuanzhong)

Love not /your gold/en dress, /I pay,

More than /your youth/ful gold/en hours.

Gather /sweet blo/ssoms while /you may,

And not /the twig/devoid /of flowers!

The source text is a seven-charactered Tang poem with the rhythm patterns of $2 / 2 / 2 / 1$ and $2 / 2 / 1 / 2$. This poem has a strong rhythm which reveals the rhythmic beauty of Tang poetry.

The target text contains four feet per line, and the source text contains four caesuras each line, both of which have a strong rhythm. The rhythm of the target text is equivalent to that of the source text. In other words, the rhythm of the target text achieves the similar effect as that of the source text. The rhythmic beauty of the source text is full-reproducible in the target language.

\section{F. Other Forms}

The above discussion is generality shared by both Tang poetry and English poetry. The following is about the translation of some other forms of Tang poetry, such as parallelism, pun, intertextuality and palindrome.

1. Parallelism

Parallelism is an inherent and essential feature of Tang poetry, especially of Lü shi. Generally speaking, parallel structure is called for in the middle (second and third) couplets of Lü shi. Of course, parallelism is also very common in English poetry. Although it is difficult to deal with parallelism in the translation process, there still exist some successful translations that fully reproduce the formal effect of parallelism in the target language. For instance,

ST: 登高 (杜甫)

无边落木萧萧下, 不尽长江滚滚来。

TT: On the Heights (Trans. Xu Yuanzhong)

The boundless forest sheds its leaves shower by shower;

The endless river rolls its waves hour by hour.

The source text is the second couplet of $\mathrm{Du}$ Fu's poem 登高, which is thoroughly parallel. The rendition of this couplet is very typical and successful. For example, the adjective "boundless" is parallel to the adjective "endless"; the noun "forest" is balanced with the noun "river", and so are the nouns "leaves" and "waves"; the verb "shed" is paired with the verb "roll"; and the phrase "shower by shower" is matched with the phrase "hour by hour". Obviously, the formal effect of parallelism is reproduced to a maximum degree in the target language.

2. Pun

Generally speaking, pun refers to a clever or humorous use of a word that has more than one meaning, or words that have different meanings but sound the same. In translating Tang poetry, it is difficult to retain the formal effect of pun in 
the target language. For instance,

ST: 无题 (李商隐)

春蚕到死丝方尽, 蜡炬成灰泪始干。

TT: To One Unnamed (Trans. Xu Yuanzhong)

The silkworm till its death spins silk from love-sick heart;

The candle but when burnt out has no tears to shed.

The source text is selected from Li Shangyin's poem 无题. It is a love poem which epitomizes and concretizes lovesickness. In the source text, the Chinese character 丝 is a pun, with the surface meaning "silk". Besides, the homonym of 丝 in Chinese is 思, which means "miss". Xu Yuanzhong translates the meaning of 丝 into "silk" and "love-sick". The words "sick" and "silk" not only share the same sound but also bear the similar form to some degree. Compared with the source text, Xu's translation merely reproduces the original meaning, but loses the formal effect of the source text.

3. Intertextuality

In Tang poetry, intertextuality means that in order to achieve some effect, the words that should be put together are to be divided into two parts in the same line or in two lines, but the meanings of the separated parts should be understood as a whole because the two separated parts are complementary to each other. In translating Tang poetry, it is almost impossible to reproduce the effect of intertextuality in the target language. For example,

ST: 出塞 (王昌龄)

秦时明月汉时关, 万里长征人未还。

TT 1: Going to the Frontier (Trans. W. Bynner)

The moon goes back to the time of Qin, the wall to the time of Han;

And the road our troops are traveling goes back three hundred miles.

TT 2: On the Frontier (Trans. Xu Yuanzhong)

The age-moon still shines o'er the ancient Great Wall;

But our frontier guardsmen have not come back at all.

The source text is the first couplet of Wang Changling's poem 出塞. The first line in the source text is a typical example of intertextuality, which means the moon in the period of the Qin and Han Dynasties shines over the Great Wall of the Qin and Han Dynasties. It expresses the concept of a very long time, but it is often misunderstood as the moon of the Qin Dynasty shines over the Great Wall of the Han Dynasty.

Bynner's translation does not convey the original meaning correctly and the effect of intertextuality is also lost in his rendition. Xu Yuanzhong's translation merely conveys the original meaning but does not reproduce the original effect in the target text, either.

4. Palindrome

Palindrome means that a word, a phrase, a line, a poem or other sequence of units can be read in the same way in either direction. There are various palindromic verses in Chinese, which can be read in different ways: from left to right, from right to left, from beginning to end, from end to beginning, from top to bottom and from bottom to top, etc. For example,

ST: 春游回文诗（王融） 池莲照晓月, 幔锦拂朝风。

TT 1: A Palindromic Verse of Spring Outing (in proper order) The lotus in the pond is being shone upon by the dawn moon, And the curtains of silk stirred by the early morn breeze.

If read from the right to the left, the source text becomes: 风朝拂锦幔, 月晓照莲池。

The resultant two lines make the same sense as the source text in proper order. The following is the translation of the resultant two lines in inverted order.

TT 2: A Palindromic Verse of Spring Outing (in inverted order)

The breeze is stirring the silk curtains at dawn,

And the moon shining upon the lotus pond in the early morn.

The source text is chosen from Wang Rong's poem 春游回文诗, which is a typical example of palindrome. The effect of palindrome is not retained in both TT 1 and TT 2 . The two renditions only convey the original meaning, but lose the formal effect of the source text. Just as Liu Zhongde (1991, p.137) argues, "Even the Chinese palindromic verse is still possible to translate in meaning, but its form can't be retained as it stands."

\section{CONCLUSION}

In this paper, the similarities and differences of poetic forms between Tang poetry (Jue ju and Lü shi) and English poetry (quatrain and ottava rima) are compared to see how the translators have dealt with the forms of Tang poetry in their translations. By comparing different translations of Tang poetry, it is found that such forms as line length, poetic 
type, rhyme, rhythm and parallelism shared by Tang poetry and English poetry can be fully reproduced in the target language. Such form as tonal pattern can be reproduced to a certain extent. However, the forms, such as pun, intertextuality and palindrome that are peculiar to Tang poetry, are difficult to be translated or untranslatable because they cannot exist outside language due to the differences of two languages.

\section{REFERENCES}

[1] Bassnett, S. \& Lefevere, A. (2001). Constructing cultures: Essays on literary translation. Shanghai: Shanghai Foreign Language Education Press.

[2] Chan, Tak-hung Leo. (2004). Twentieth-century Chinese translation theory: Modes, issues and debates. Amsterdam \& Philadelphia: John Benjamins Publishing Company.

[3] Gao Yukun. (1994). On English translation of Tang poetry. Journal of University of International Relations, (4), 21-29.

[4] Gu Zhengkun. (2006). China and West: Comparative poetics and translatology. Beijing: Tsinghua University Press.

[5] Guo Ying. (2006). On aesthetic constituents in poetry translation: Aesthetic subjects and objects in translation of Tang poetry. Unpublished master's thesis, Liaoning Normal University, Dalian, China.

[6] Holmes, J. S. (1994). Translated! Papers on literary translation and translation studies. Amsterdam: Rodopi.

[7] HuangYuanshen \& Zhou Liren. (2003). Appreciation and criticism of foreign literature. Shanghai: Shanghai Foreign Language Education Press.

[8] Jiang Feng. (1995). A second thought on similarity in form and in content. Journal of Chongqing University, 1 (2), 103-109.

[9] Lefevere, A. (1975). Translating poetry: Seven strategies and a blueprint. Assen/Amsterdam: Van Gorcum.

[10] Li Hongqi. (2009). Sound pattern, form and meaning: Exploration of Tang poetry translating and appreciation. Unpublished master's thesis, Chongqing Normal University, Chongqing, China.

[11] Liu Yingkai. (1989). Further discussion on "sound beauty" theory. Modern Foreign Languages, 44 (2), 36-41.

[12] Liu Zhongde. (1991). Ten lectures on literary translation. Beijing: China Translation \& Publishing Corporation.

[13] Lü Shuxiang. (Ed.). (1980). A comparative study on English translations of old gems. Shanghai: Shanghai Foreign Language Education Press.

[14] Sun Dayu. (2007). An anthology of the Tang Dynasty poetry. Shanghai: Shanghai Foreign Language Education Press.

[15] Tan Zaixi. (2004). A short history of translation in the West (Rev. ed.). Beijing: The Commercial Press.

[16] Waley, A. (1962). A hundred and seventy Chinese poems. London: Constable.

[17] Wu Dilong. (2010). On translation of Chinese classical poetry in the perspective of intertextuality. Unpublished doctoral dissertation, Shanghai International Studies University, Shanghai, China.

[18] Xu Jun. (2003). On the paradox between form and spirit. Journal of Foreign Languages, 144 (2), 57-66.

[19] Xu Xiufeng. (2006). On the aesthetic transference of poetry translation: Xu Yuanzhong's thought on poetry translation. Unpublished master's thesis, Ocean University of China, Qingdao, China.

[20] Xu Yuanzhong. (1984). The art of translation. Beijing: China Translation \& Publishing Corporation.

[21] Xu Yuanzhong. (1992). On Chinese verse in English rhyme. Beijing: Peking University Press.

[22] Xu Zhongjie. (1990). Two hundred Chinese poems in English verse. Beijing: Beijing Language and Culture College Press.

[23] Yang Zijian \& Liu Xueyun. (Eds.). (2003). New theories on translation. Wuhan: Hubei Education Press.

[24] Zhang Tingchen \& Wilson, B. M. (1991). One hundred Tang poems. Beijing: China Translation \& Publishing Corporation.

[25] Zhang Zhizhong. (2007). Poetic form and English translation of Chinese poetry. Journal of Tianjin Foreign Studies University, $14(5), 33-42$.

[26] Zhou Liuxi. (2006). An overview of poetic metrics. Research in Foreign Language and Literature, 16 (2), 1-8.

[27] Zhu Guangqian. (2008). On poetry. Nanjing: Jiangsu Literature and Art Publishing House.

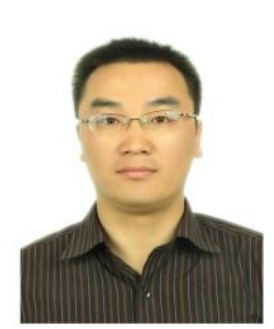

Tingshu Hu was born in Huai'an, China in 1977. He received his M.A. degree in English language and literature from Nanjing Agricultural University, China in 2010.

He is currently a lecturer in the Faculty of Foreign Languages, Huaiyin Institute of Technology, Huai'an,

China. His research interests include translation theory and practice \& intercultural communication.

Mr. Hu is a member of the Translators Association of China and the Poets Association of Jiangsu. 